\title{
ANNUAL SIGNALS OBSERVED IN REGIONAL GPS NETWORKS
}

\author{
Janusz Bogusz * and Mariusz Figurski \\ Faculty of Civil Engineering and Geodesy, Military University of Technology, \\ 00-908 Warsaw, Kaliskiego St. 2, Poland \\ *Corresponding author's e-mail: jbogusz@wat.edu.pl
}

\section{ARTICLE INFO}

Article history:

Received 14 January 2014

Accepted 27 February 2014

Available online 7 March 2014

Keywords:

GPS

ASG-EUPOS

Seasonal signal

\section{ABSTRACT}

This paper describes analyses concerning annual signals in GPS-derived coordinates. The data was processed in the Military University of Technology Local Analysis Centre with Bernese 5.0 software. We used observations from 129 permanent GPS stations which belong to the Polish Active Geodetic Network (ASG-EUPOS), for the period of GPS weeks 1465-1729, corresponding to about 5 years. The annual signals have been estimated using the Least Squares Estimation (LSE) with assumption of stationarity of amplitude and phase, and uncertainties calculated with the coloured noise assumption using the First Order Gauss Markov model (FOGM). The phase was defined as the time span from the beginning of the year to the maximum of the best-fitting sinusoid. The data was analysed using the TSView software (Herring, 2003). Amplitudes of best-fitting sinusoids into the North components range between 0.1 and $3.5 \mathrm{~mm}$, the East component: 0.1-4.1 mm, the Up component: 0.1-4.0 $\mathrm{mm}$ with similar uncertainties of 0.1-0.3 mm. The phase shifts are unevenly distributed over the considered area, no clearly visible spatial dependencies were discovered. The North and East components reveal clearly maximums concentrated over winter- (January and February) and summer-time (JuneJuly). They could be explained by the hydrological and atmospheric (including thermal) influences. However, this theory does not seem to be supported by the Up distribution with no clearly visible extreme values. We noticed that the velocity bias due to annual oscillation could range from -0.6 to $+0.5 \mathrm{~mm} / \mathrm{y}$, but when we look at the issue relatively we can mismodel the North and East velocity by $3.4 \%(0.5$ of $14.8 \mathrm{~mm} / \mathrm{y})$, while the Up velocity at the tectonically stable areas considered in this publication could be mismodelled by even $600 \%$ $(0.6$ of $0.1 \mathrm{~mm} / \mathrm{y})$

\section{INTRODUCTION}

The individual component (North, East or Up) of GPS time series can be described as the sum of:

$$
\begin{aligned}
x(t)= & x_{0}+v_{x} \cdot t+\sum_{i=1}^{n}\left[A_{i} \cdot \sin \left(\omega_{i} \cdot t+\varphi_{i}\right)\right]+ \\
& +O_{x}+\sum_{j=1}^{m} p_{j} \cdot x_{j}^{\text {off }}+\varepsilon_{x}(t)
\end{aligned}
$$

where:

$x_{0}-$ initial value;

$v_{x} \cdot t-$ the linear trend (velocity);

$O_{x}, \sum_{j=1}^{m} p_{j} \cdot x_{j}^{o f f}-$

outliers and offsets (removed at the pre-processing stage);

$\varepsilon_{x}(t)$ - residuals (measure of accuracy);

$\sum_{i=1}^{n}\left[A_{i} \cdot \sin \left(\omega_{i} \cdot t+\varphi_{i}\right)\right]-$

seasonal variations: in daily GPS solutions annual and its harmonics.

The seasonal position variations due to geophysical loading effects associated with the large- scale transport of the fluids (e.g. van Dam et al., 2001; van Dam and Wahr, 1987) have to be mentioned first. Blewitt and Lavallée (2002) showed annual variation in GPS station coordinates with typical amplitudes of $2 \mathrm{~mm}$ for horizontal and $4 \mathrm{~mm}$ for vertical components. The analysis in local European GPS networks showed oscillations of similar magnitude (e.g. Bogusz et al., 2011; Rajner and Liwosz, 2011). However, significant part of this oscillation could be explained by artefacts in GPS system itself (Dong et al., 2002). Penna and Stewart (2003) showed the possible mechanism of aliasing of unmodeled errors at tidal frequencies in the diurnal and semidiurnal bands to longer periods. They proved on a 10-year span of simulated data that insufficient modelling in K1 (GPS repeatability period) can cause artificial annual oscillation in 24-hour processing, while in K2 (GPS orbiting period) may introduce semi-annual variations. The case study of ASG-EUPOS (Bogusz and Figurski, 2012) confirmed the existing residual oscillations in K1, S1 and K2 frequencies of several millimetres. For a possible explanation the multipath biases, sitespecific environmental changes (e.g. snow coverage), antenna phase centre modelling (Hatanaka et al., 2001), orbit errors and data quality metrics (Ray et al., 2005; Ray, 2006) have to be mentioned. 
But the annual signal in the GPS time series has to be understood twofold:

1. tropical year (365.2421 days): time that the Earth takes to return to the same position with respect to the Sun;

2. draconitic year (351.2 days): time that the constellation of GPS satellites takes to return to the same position with respect to the Sun (Ray et al., 2008).

However, Rebischung et al. (2012) stated that simultaneous estimation of annual and draconitic harmonics does not significantly improve the agreement between GPS and loading model at the annual frequency, because these residual signals have similar periods and magnitudes.

\section{ANNUAL SIGNALS: ASG-EUPOS CASE STUDY}

We used as input of our analyses the coordinates generated in the ITRF2008 (Altamimi et al., 2011) reference frame. The GPS processing was made in the Military University of Technology Local Analysis Centre using the Bernese 5.0 GNSS software (Dach et al., 2007). The described solution is consistent with the EPN (EUREF Permanent Network) guidelines (Bruyninx et al., 2009) and covered 5 years (GPS weeks 1465-1729). Only GPS observations were processed. The network is shown in Figure 1.

Each geocentric coordinate position was transformed into the North-East-Up topocentric reference frame first. Figure 2 presents an exemplary time series from the BOGI (Borowa Góra, Poland) GPS station with formal RMS errors taken from the GPS processing (stored into the SINEX files), which typically was about $1 \mathrm{~mm}$.

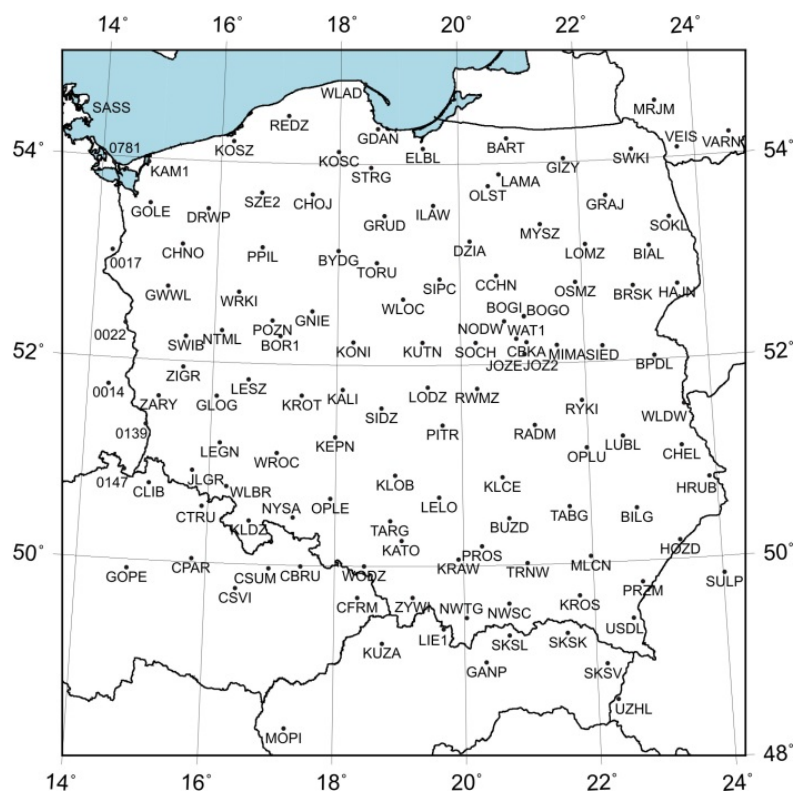

Fig. 1 Layout of the ASG-EUPOS permanent stations.

The best-fitting sinusoid for each component (NEU) could be described by the following equation:

$y=A \cdot \sin (\omega t+\varphi)$

where $\omega=2 \pi \frac{\mathrm{rad}}{\text { year }}$ is the angular velocity of one

year, $A$ and $\phi$ are amplitude and phase shift, respectively. The analysis of the data was done using the TSView software (Herring, 2003), applying
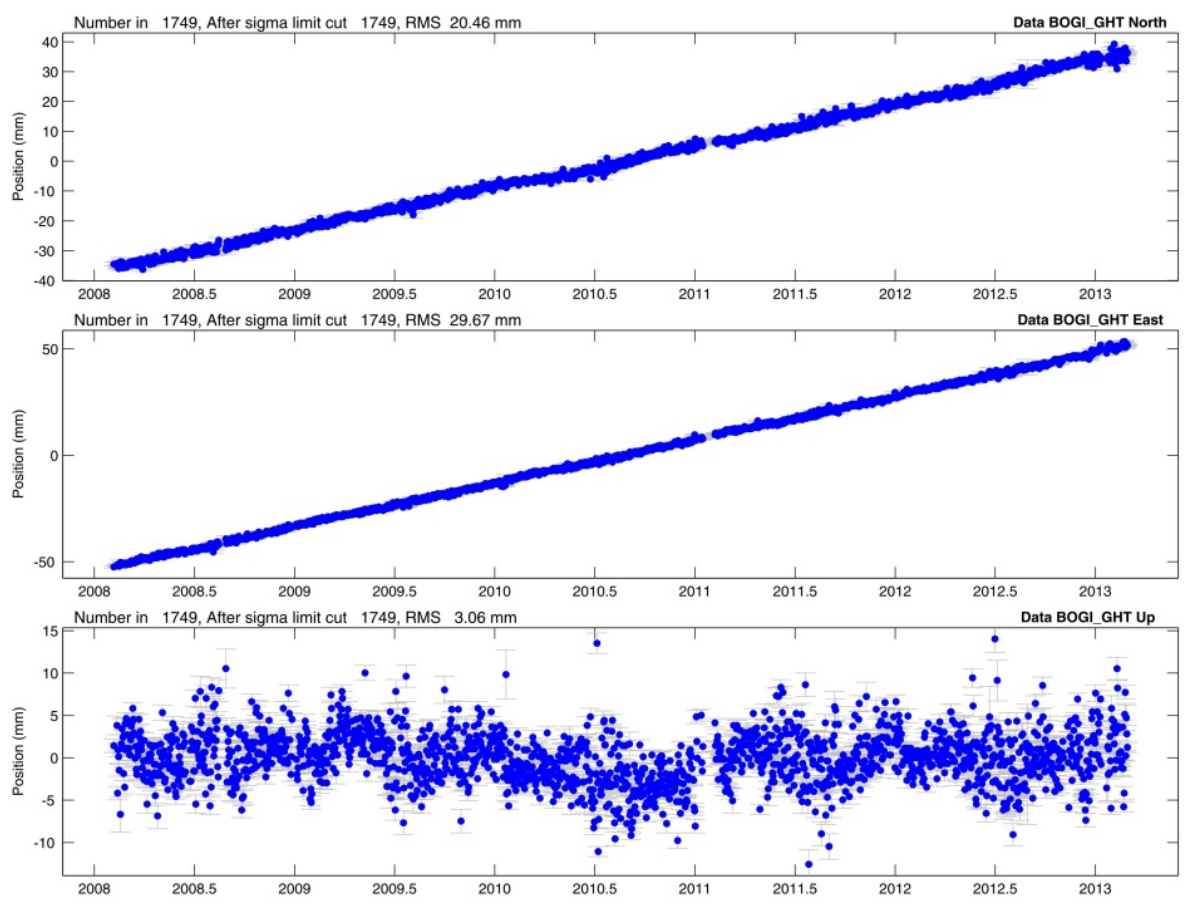

Fig. 2 Changes of the North, East and Up components of BOGI (Borowa Góra, Poland) ASG-EUPOS site. 
Table 1 Amplitudes and phases of the selected GPS stations with the uncertainties (FOGM Model).

\begin{tabular}{lrrrrrrrrrrrrr}
\hline \multirow{3}{*}{ Station } & \multicolumn{1}{c}{ North } & $\begin{array}{c}\text { A } \\
{[\mathrm{mm}]}\end{array}$ & $\begin{array}{c}\text { RMS } \\
{[\mathrm{mm}]}\end{array}$ & $\begin{array}{c}\phi \\
{[\mathrm{month}]}\end{array}$ & $\begin{array}{c}\text { RMS } \\
{[\mathrm{month}]}\end{array}$ & $\begin{array}{c}\text { A } \\
{[\mathrm{mm}]}\end{array}$ & $\begin{array}{c}\text { RMS } \\
{[\mathrm{mm}]}\end{array}$ & $\begin{array}{c}\phi \\
{[\text { month }]}\end{array}$ & $\begin{array}{c}\text { RMS } \\
{[\mathrm{month}]}\end{array}$ & $\begin{array}{c}\text { A } \\
{[\mathrm{mm}]}\end{array}$ & $\begin{array}{c}\text { RMS } \\
{[\mathrm{mm}]}\end{array}$ & $\begin{array}{c}\phi \\
{[\mathrm{month}]}\end{array}$ & $\begin{array}{c}\text { RMS } \\
{[\mathrm{month}]}\end{array}$ \\
\hline TARG & 3.5 & 0.08 & 6.4 & 0.0 & 0.6 & 0.05 & 5.9 & 0.2 & 0.2 & 0.28 & 7.7 & 2.1 \\
WLAD & 3.5 & 0.12 & 0.6 & 0.1 & 4.1 & 0.11 & 6.9 & 0.1 & 2.5 & 0.54 & 2.0 & 0.4 \\
SKSK & 3.4 & 0.15 & 0.5 & 0.1 & 1.8 & 0.10 & 0.5 & 0.1 & 0.4 & 0.71 & 7.7 & 3.1 \\
GNIE & 2.5 & 0.32 & 5.6 & 0.2 & 2.2 & 0.21 & 0.2 & 0.2 & 0.1 & 0.40 & 5.3 & 14.3 \\
BPDL & 2.3 & 0.10 & 6.5 & 0.1 & 1.8 & 0.13 & 6.2 & 0.1 & 1.1 & 0.26 & 7.5 & 0.5 \\
BRSK & 2.1 & 0.17 & 0.0 & 0.2 & 1.3 & 0.10 & 5.9 & 0.2 & 0.5 & 0.43 & 0.9 & 1.6 \\
KLCE & 2.1 & 0.13 & 6.0 & 0.1 & 1.0 & 0.08 & 5.8 & 0.2 & 0.9 & 0.21 & 6.5 & 0.4 \\
DRWP & 2.0 & 0.34 & 12.0 & 0.3 & 0.4 & 0.26 & 6.8 & 1.3 & 1.7 & 0.78 & 11.9 & 0.9 \\
\hline
\end{tabular}

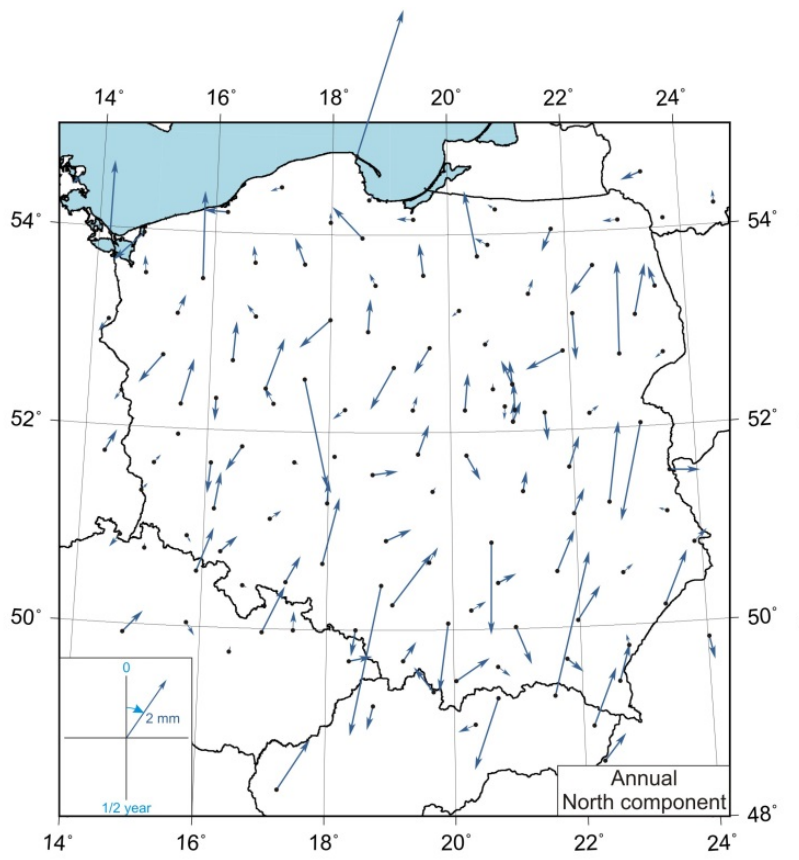

Fig. 4 Annual signal in the North component.

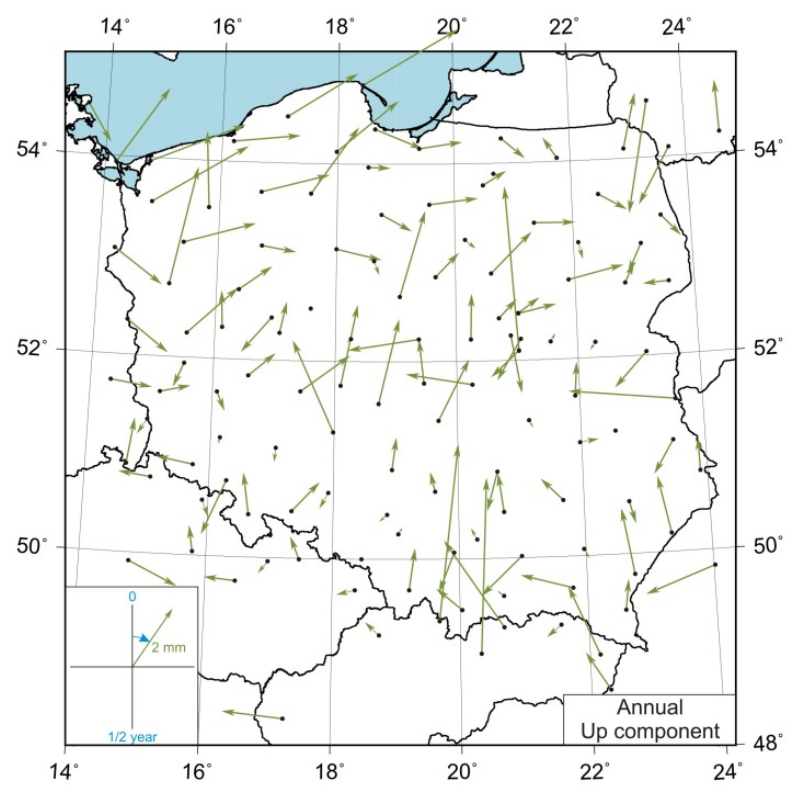

Fig. 6 Annual signal in the Up component.

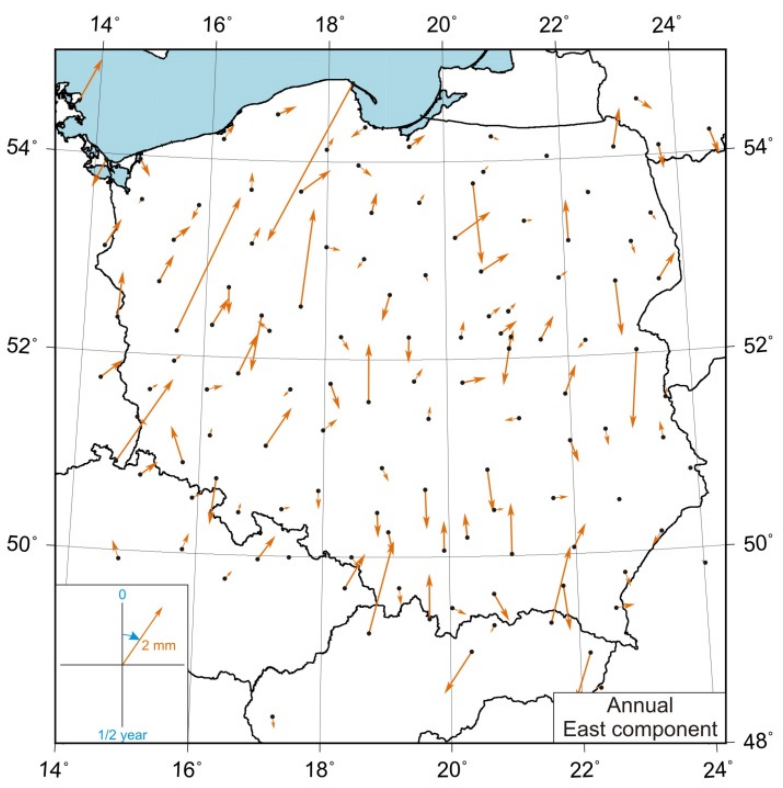

Fig. 5 Annual signal in the East component.

3 -sigma criterion for outlier detection. The amplitude and phase were determined by means of the Least Squares Estimation (LSE) with uncertainties calculated with the coloured noise assumption by means of the First Order Gauss Markov Model (FOGM). In this research, phase is defined as the time span from the beginning of the year to the maximum of the best-fitting sinusoid (Fig. 3).

Table 1 presents amplitudes and phases of the selected GPS stations (those of maximum amplitudes in the North component were chosen). Values of RMSs (0.1 to $0.3 \mathrm{~mm})$ from 5-year time series demonstrate the reliability of the determination.

Figures 4-6 show amplitudes and phase shifts of the annual oscillations for the three coordinate components for all considered stations. The length of the arrow represents the amplitude, while phase (0-2 months) is analogous to the geodetic azimuth. Amplitudes of best-fitting sinusoids into the North components (Fig. 4) range between 0.1 and $3.5 \mathrm{~mm}$, 
the East component (Fig. 5): 0.1-4.1 mm, the Up component (Fig. 6): 0.1-4.0 mm. The phase shifts are unevenly distributed over the considered area. Similar results were shown for the EPN network in the paper by Kenyeres and Bruyninx (2009). No clearly visible spatial dependencies were discovered. The most likely explanation could be the imposition of the possible causes of annuals signals mentioned in the first chapter of this paper.

Figures 7a-c show the distribution of the phases (in months). For interpretation purposes the bestfitting polynomial curve was plotted. The North (Fig. 7a) and East (Fig. 7b) components reveal clearly maximums concentrated over winter- (January and February) and summer-time (June-July). They could be explained by the hydrological and atmospheric (including thermal) influences. However, this theory does not seem to be supported by the Up distribution (Fig. 7c) with no clearly visible extreme values. In this case the superposition with artefacts of the system (of higher magnitude in this component, but of random phase) could take place.

Referring to equation (1) it should be stated that all of the periodical components have to be efficiently determined before determination of the linear trend. According to the publication by Gross et al. (2009) the velocities determined from the permanent GPS observation have to fulfil the requirement for being "stable at $0.1 \mathrm{~mm} / \mathrm{y}$ ". The annual signals can significantly bias the velocity determination. In the considered case, this bias can range from -0.6 to $+0.5 \mathrm{~mm} / \mathrm{y}$ (Fig. 8 ), but when we look at the issue relatively we can mismodel the North and East velocity by $3.4 \%$ ( 0.5 of $14.8 \mathrm{~mm} / \mathrm{y})$, while the Up velocity at the tectonically stable areas considered in this publication could be mismodelled by even $600 \%(0.6$ of $0.1 \mathrm{~mm} / \mathrm{y})$.

Figures 9-11 present the differences in the velocity determination (with and without estimating annual signals) as a function of the amplitude of annual signal itself. These results are ambiguously interpreted. Many of the results concentrate around zero difference, which is obvious since absence of an annual signal is not influencing the linear trend estimation (Fig. 11). Moreover, in case of the East component (Fig. 10) the same amplitude of annual oscillation (about $2.2 \mathrm{~mm}$ ) caused slightly various velocity difference ranging from -0.1 to $-0.7 \mathrm{~mm} / \mathrm{y}$. Among the potential explanations for this, the existence of other, than annual, periods should be mentioned. Furthermore, the length of the interval and especially position of maxima at starting and ending time intervals are an additional reason for obtained differences.

\section{SUMMARY}

A major component of annual signals is now known to be true physical motion (Blewitt et al., 2001). The solutions to this problem could be:
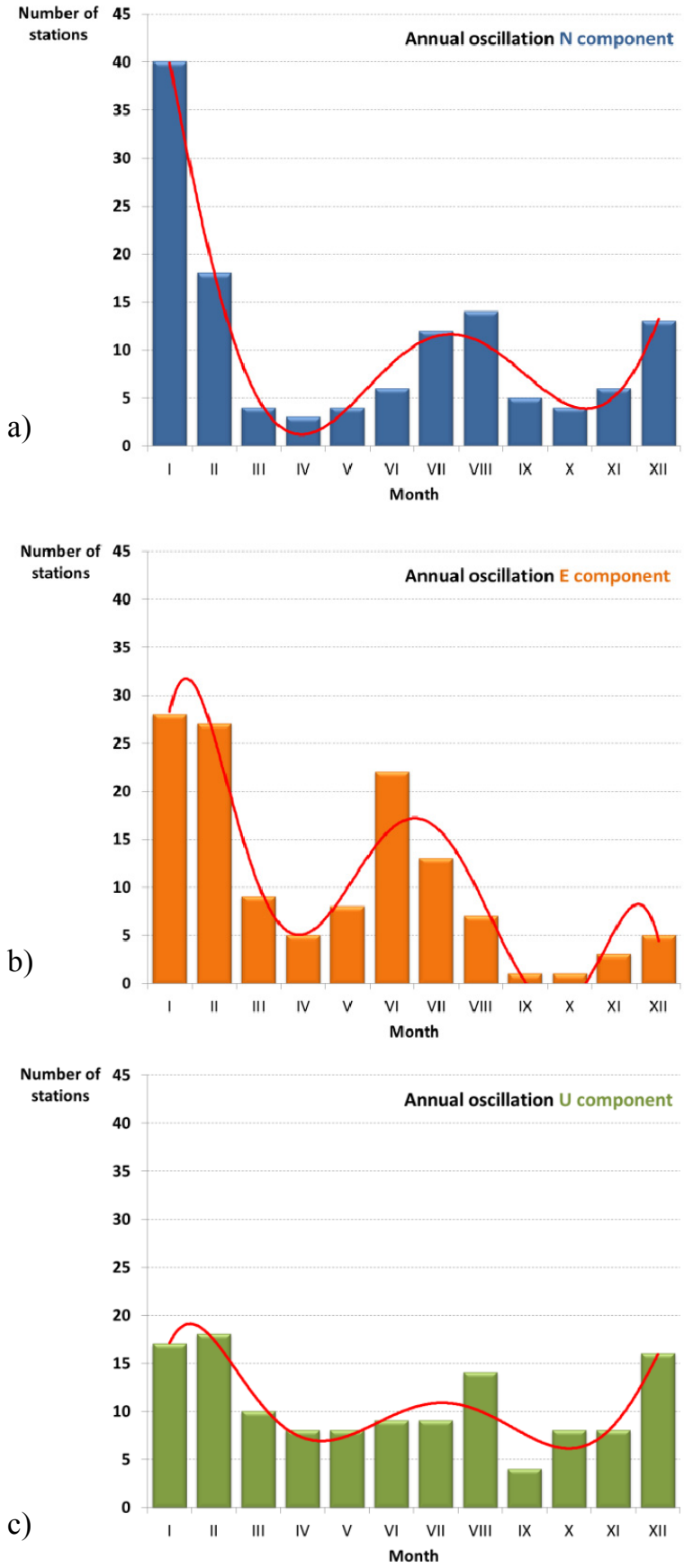

Fig. 7 Frequencies of the annual oscillations in the North (a), East (b) and Up (c) components with respect to the phase shift.

- to estimate the annual signal at the processing stage (the newest Bernese 5.2 version offers such solutions);

- to use available hydrological models to improve GPS-derived residuals (e.g. GRACE);

- to estimate the annual signal simultaneously with site velocities with more sophisticated algorithms (e.g. Singular Spectrum Analysis) than LSE. 


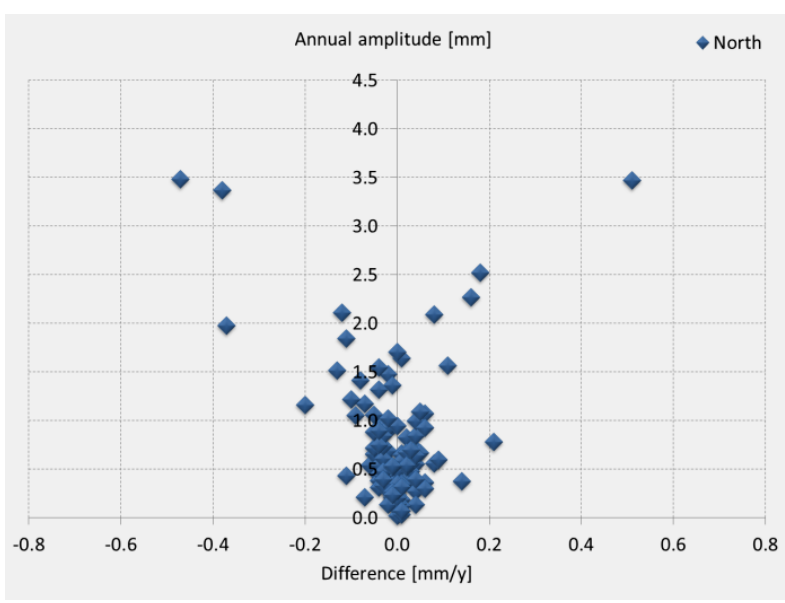

Fig. 9 Difference in the velocity estimation versus the amplitude of annual signal of the North component.

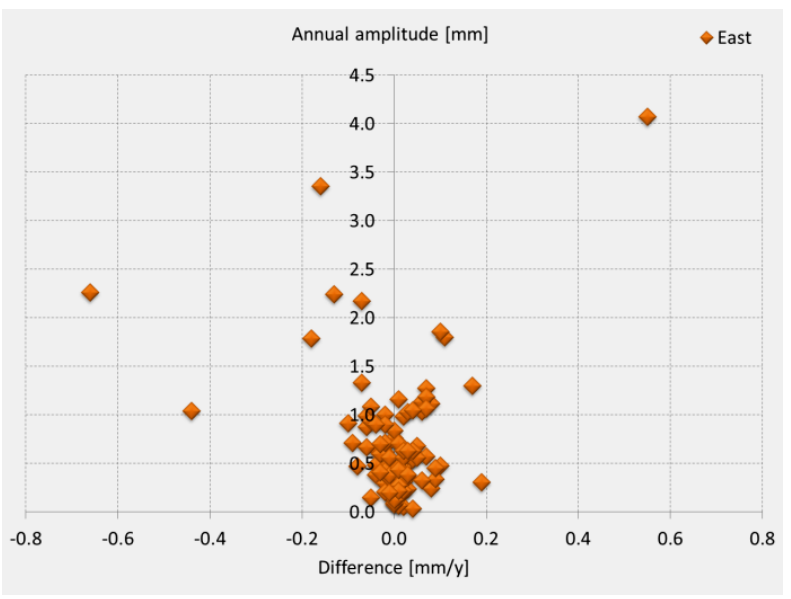

Fig. 10 Difference in the velocity estimation versus the amplitude of annual signal of the East component.

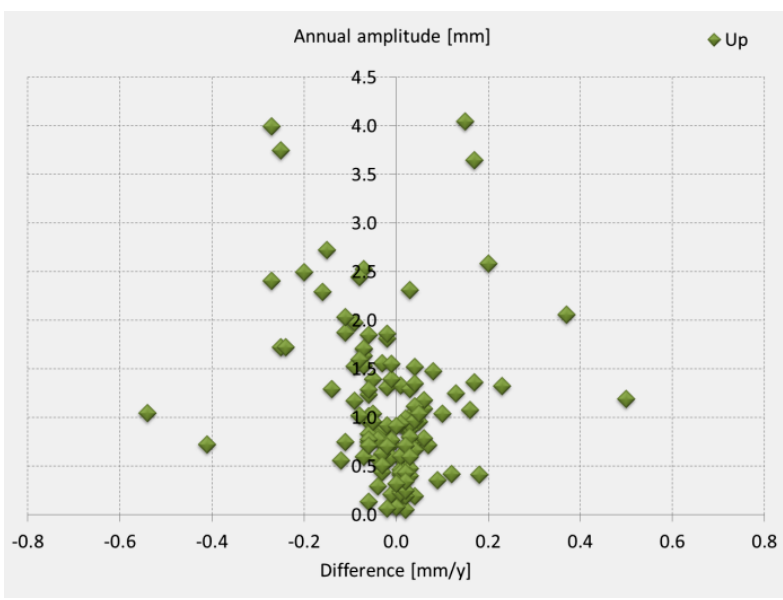

Fig. 11 Difference in the velocity estimation versus the amplitude of annual signal of the Up component.
It is reasonable to estimate the annual signal together with the site velocity (Blewitt and Lavallée, 2002), having in mind that annually repeating signal contains not only an annual sinusoid, but also its harmonics. Estimation of only the annual amplitude and phase might not mitigate the entire effect. The possible explanation of the sources of annual signals in the residual GPS time series could be brought by the analysis aimed at the spatial coherence (e.g. common modelling errors: Wdowinski et al., 1997). Analyses at co-located sites will also be valuable.

\section{ACKNOWLEDGMENTS}

Many thanks to Dr. Ambrus Kenyeres and the other, anonymous, Reviewer for several comments which helped to improve the paper.

This research was financed by the Faculty of Civil Engineering and Geodesy of the MUT statutory research funds.

\section{REFERENCES}

Altamimi, Z., Collilieux, X. and Metivier, L.: 2011, ITRF2008: an improved solution of the International Terrestrial Reference Frame. Journal of Geodesy, 85, issue 8, 457-473, DOI: 10.1007/s00190-011-0444-4

Blewitt, G., Lavallée, D., Clark, P. and Nurutdinov, K.: 2001, A new global model of Earth deformation: seasonal cycle detected, Science, 294, 2342-2345. DOI: $10.1126 /$ science. 1065328

Blewitt, G. and Lavallée, D.: 2002, Effect of annual signals on geodetic velocity. J. Geophys. Res., 107(B7), 2145. DOI: 10.1029/2001JB000570

Bogusz, J. and Figurski, M.: 2012, GPS-derived height changes in diurnal and sub-diurnal timescales. Acta Geophysica, 60, no. 2, 295-317. DOI: $10.2478 / \mathrm{s} 11600-011-0074-5$

Bogusz, J., Figurski, M., Kroszczyński, K. and Szafranek, K.: 2011, Investigation of environmental influences to the precise GNNS solutions. Acta Geodyn. Geomater., 8, No. 1 (161), 5-15.

Bruyninx, C., Altamimi, Z., Caporali, A., Kenyeres, A., Lidberg, M., Stangl, G. and Torres, J.A.: 2009, Guidelines for EUREF Densifications. Available electronically at:

$\mathrm{ftp} / /$ epncb.oma.be/pub/general/Guidelines for EURE F Densifications.pdf.

Dach, R., Hugentobler, U., Fridez, S. and Meindl, M. (eds.): 2007, Bernese GPS software version 5.0. Astonomical Institute, the University of Bern.

Dong, D., Fang, P., Bock, Y., Cheng, M. K. and Miyazaki, S.: 2002, Anatomy of apparent seasonal variations from GPS-derived site position time series. J. Geophys. Res., 107(B4), 2075. DOI: 10.1029/2001JB000573

Gross, R., Beutler, G., and Plag, H.-P.: 2009, Integrated scientific and societal user requirements and functional specifications for the GGOS. In: H.-G. Plag, M. Pearlman (eds.), Global Geodetic Observing System: Meeting the Requirements of a Global Society on a Changing Planet in 2020, Springer, Berlin, 209-224.

Hatanaka, Y., Sawada, M., Horita, A., Kusaka, M., Johnson, J. and Rocken, C.: 2001, Calibration of antennaradome and monument-multipath effect of 
GEONET-Part 2: Evaluation of the phase map by GEONET data. Earth Planets Space 53, 23-30.

Herring, T.A.: 2003, MATLAB Tools for viewing GPS velocities and time series. GPS Solutions, 7, No. 3, 194-199. DOI: 10.1007/s10291-003-0068-0

Kenyeres, A. and Bruyninx, C.: 2009, Noise and periodic terms in the EPN time series. Geodetic Reference Frames, International Association of Geodesy Symposia, 134, 143-148.

Penna, N.T. and Stewart, M. P.: 2003, Aliased tidal signatures in continuous GPS height time series. Geophys. Res. Lett., 30(23), 2184. DOI:10.1029/2003GL018828

Rajner, M. and Liwosz, T.: 2011, Studies of crustal deformation due to hydrological surface loading on GPS height estimates. Geodesy and Cartography 60 , 2, 137-146. DOI: $10.2478 / \mathrm{v} 10277-012-0012-y$

Ray, J.: 2006, Systematic errors in GPS position estimates. Presentation at IGS 2006 workshop, Darmstadt (available electronically at nng.esoc.esa.de/ws2006/ERRO6.pdf).

Ray, J., Gendt, G., Ferland, R. and Altamimi, Z.: 2005, Short-term instabilities in the IGS reference frame. Geophys Res Abstr, 7, 02864.
Ray, J., Altamimi, Z., Collilieux, X. and van Dam, T.: 2008, Anomalous harmonics in the spectra of GPS position estimates. GPS Solut, 12, 55-64. DOI 10.1007/s10291-007-0067-7

Rebischung, P., Collilieux, X., van Dam, T., Ray, J. and Altamimi, Z.: 2012, Analysis effects in IGS station motion time series. Presented at the IGS workshop 2012, Olsztyn, Poland.

van Dam, T.M. and Wahr, J.: 1987, Displacements of the Earth's surface due to atmospheric loading: Effects on gravity and baseline measurements. J Geophys Res 92 , 1281-1286. DOI: 10.1029/JB092iB02p01281

van Dam, T., Wahr, J., Milly, P.M., Shmakin, A., Blewitt, G., Lavallée, D. and Larson, K.: 2001, Crustal displacements due to continental water loading, Geophysical Research Letters, 28, No. 4, 651-654. DOI: 10.1029-2000GL012120

Wdowinski, S., Bock, Y., Zhang, J., Fang, P. and Gengrich, J.: 1997, Southern California permanent GPS geodetic array: Spatial filtering of daily positions by estimating coseismic and postseismic displacement induced by the 1992 Landers eqrthquake. J. Geophys. Res., 102, issue B8, 18 057-18 070. DOI: 10.1029/97JB01378 


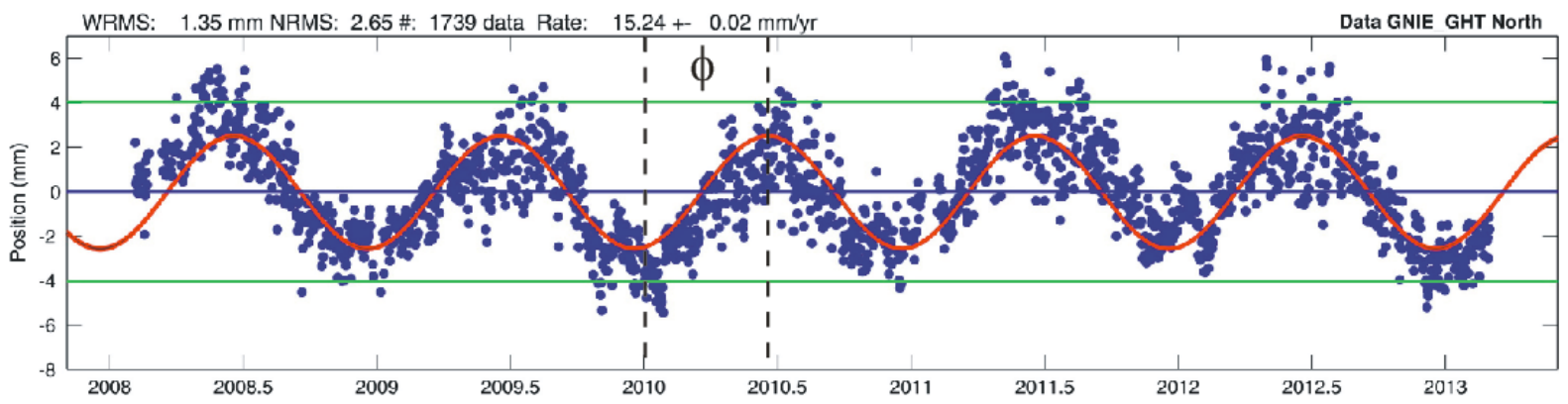

Fig. 3 Visualisation of the phase shift interpretation on GNIE (Gniezno, Poland) GPS time series for the North component.

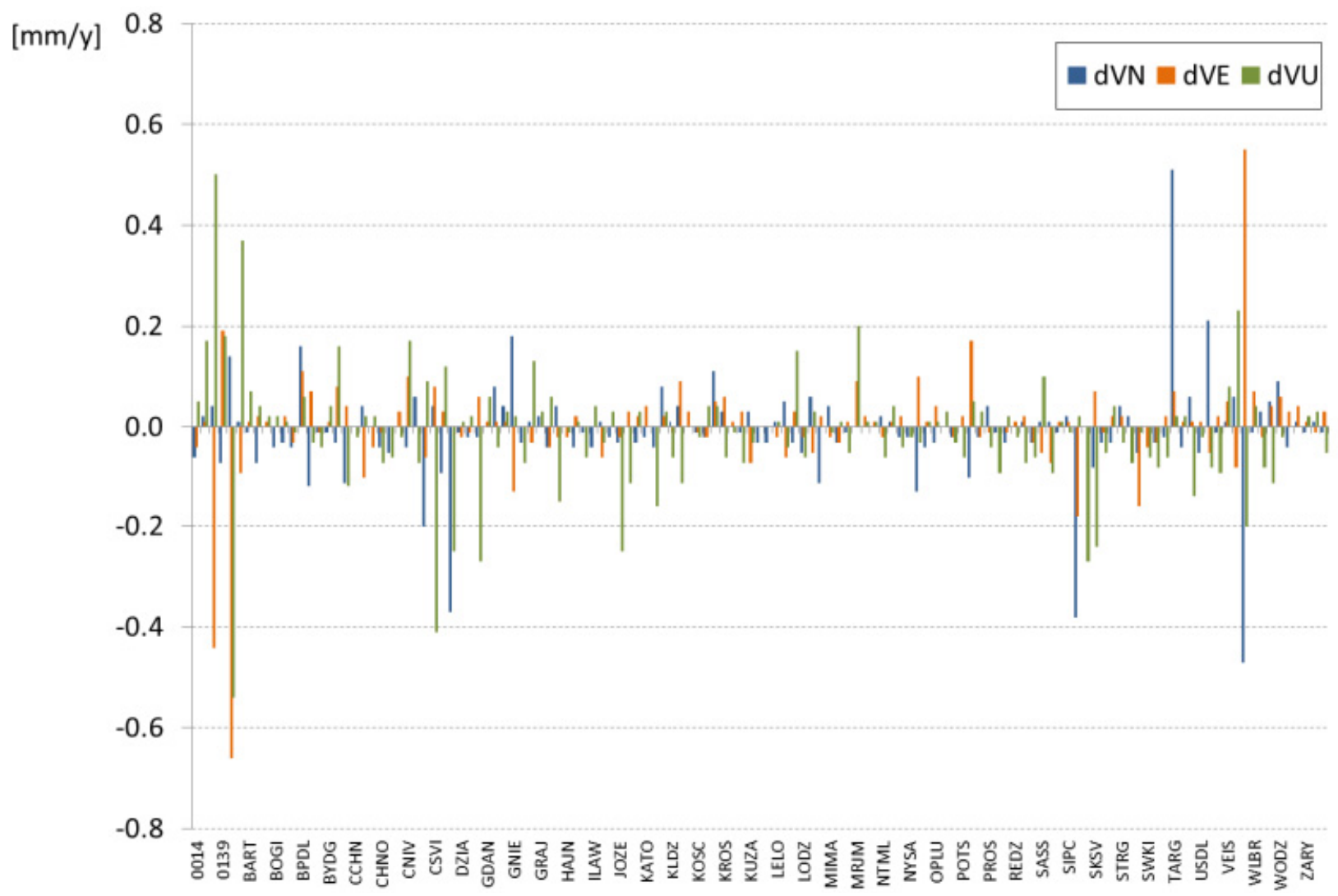

Fig. 8 The differences in the estimation of velocity, with and without taking into account the annual oscillation. 